\title{
Delayed effects of subarachnoid haemorrhage on cerebral metabolism and the cerebrovascular response to hypercapnia in the primate
}

\author{
D.P. J. B O IS VER T, J. D. P I CKAR D, D. I. GR A H A M, \\ A N D W. F I T C H
}

From the Wellcome Surgical Research Institute and the Departments of Neurosurgery, Neuropathology, and Anaesthesia, University of Glasgow, Glasgow

SUMMARY A technique is described for the production of subarachnoid haemorrhage in baboons and their subsequent recovery for chronic study of cerebrovascular reactivity. The baboons make complete neurological recoveries but the response of their cerebral circulation to $\vec{\rho}$ hypercapnia is impaired one week later. Baseline values of cerebral blood flow and of cerebral oxygen consumption are unaffected at this time. There is no evidence of hypoxic brain damage.

The aetiology of cerebral ischaemia associated with subarachnoid haemorrhage remains poorly defined. Cerebral ischaemia occurs naturally after subarachnoid haemorrhage but often appears to be aggravated by surgical intervention, particularly when this is carried out during the first week after rupture of the aneurysm. While angiographic "vasospasm" and neurological deficit often develop simultaneously, there can be marked discrepancies between the clinical state and the angiographic appearances (Millikan, 1975; Fisher et al., 1977; Adams et al., 1978). It is very difficult to determine in the individual patient whether there has been a sufficient reduction in local blood flow, at some stage after subarachnoid haemorrhage, to produce a partial or total arterial territory infarction. On the basis of our previous work with acute subarachnoid haemorrhage in monkeys in Edmonton (Petruk et al., 1973, 1974; Boisvert et al., 1978), and on experimental spasm and proximal vessel occlusion in baboons in Glasgow (Harper et al., 1972; Jennett et al., 1976), we have developed a baboon preparation with which to study the more chronic effects of subarachnoid haemorrhage on the reactivity of the cerebral circulation and the associated neuropathological sequelae. Previous experimental studies of subarachnoid haemorrhage in animals

Address for reprint requests: Mr J. D. Pickard, Department of Neurosurgery, Institute of Neurological Sciences, Southern General Hospital, Glasgow G51 4TF, Scotland.

Accepted 4 April 1979 have been limited to the acute effects, extendint beyond 48 hours after the induction of haemort rhage only for angiographic studies or baselinf 을 measurements of cerebral blood flow. In suct acute studies it has not been possible to dissociate the changes in cerebrovascular reactivity from changes in intracranial pressure, cerebral met bolism and CSF acid-base balance (Löfgren an Zwetnow, 1972; Hashi et al., 1972a).

\section{Methods}

\section{STAGE 1}

Young adult baboons (10-20 kg), tranquillised with phencyclidine $(12 \mathrm{mg}$ im) were anaesthetised with thiopentone $(7.5 \mathrm{mg} / \mathrm{kg}$ iv) and halothane $0.5 \%$ in nitrous oxide $70 \%$ and oxygen. Endotracheal intubation was performed and ventilation was controlled. The suprachiasmatic cistern was punctured with a needle (22G spinal needle) passed percutaneously through the optic foramen without enucleation of the orbit. A similar technique has been described in the dog (McQueen and Jeanes, 1962). Free flow of CSF was obtained. One operator (JDP) always performed this technique to minimise the failure rate. A small incision over one femoral artery was made, and $0.75 \mathrm{ml} / \mathrm{kg}$ arterial blood withdrawn and injected manually into the suprachiasmatic cistern over 30 seconds. Hypoxic brain damage caused by a transient respiratory arrest was avoided by artificial positive pressure ventilation. Anaesthesia was 
discontinued and the animals were returned to their cage. This injection technique was found to be more convenient in the baboon than the transfrontal method developed for the rhesus monkey in Edmonton (Boisvert et al., 1978).

Boisvert et al. (1977, 1978) have found in separate experiments that injection of mock cerebrospinal fluid into the suprachiasmatic cistern produces the same pattern of immediate rise in intracranial pressure as does the injection of blood but that there is no effect on intracranial arterial diameter, baseline cerebral blood flow or the autoregulatory response to changing blood pressure. At no point on its path to the suprachiasmatic cistern does the needle for the transorbital injection of blood touch the internal carotid artery, and at no time was arterial blood obtained on withdrawal of the stylet.

\section{STAGE 2}

One week later the animals were sedated with phencyclidine $(12 \mathrm{mg}$, im), and anaesthesia was then induced with sodium thiopentone $(7.5 \mathrm{mg} /$ $\mathrm{kg}$, iv). After endotracheal intubation, anaesthesia was maintained by half-hourly injections of phencyclidine $(2-4 \mathrm{mg}, \mathrm{im})$ and with $70 \% \mathrm{~N}_{2} \mathrm{O}-$ $30 \% \quad \mathrm{O}_{2}$ delivered by an intermittent positive pressure respiratory pump in open circuit. Muscular relaxation was provided with suxamethonium chloride $(50 \mathrm{mg}$, im) administered at half hourly intervals. End-tidal $\mathrm{CO}_{2}$ was monitored continuously with an infrared analyser and controlled either by altering the stroke volume of the pump or by adding $\mathrm{CO}_{2}$ to the inspired gas mixture. The $\mathrm{PaO}_{2}$ was always maintained above $80 \mathrm{mmHg}$. A catheter was inserted into the abdominal aorta, via a femoral artery, for the measurement of arterial blood pressure and for the withdrawal of blood samples for the measurement of $\mathrm{PCO}_{2}, \mathrm{pH}, \mathrm{PO}_{2}$, oxygen content, and haemoglobin concentration. A slow saline drip was given via a femoral vein catheter. Body temperature was maintained close to $37^{\circ} \mathrm{C}$ by the use of a heating blanket and infrared lamps.

Cerebral blood flow was measured from the parietal area of the brain with a collimated one inch sodium iodide scintillation crystal and calculated by the height/area method (HøedtRasmussen et al., 1966) after the intracarotid injection of xenon-133 via a catheter in the right linguofacial trunk. The remaining branches of the right external carotid artery were ligated, and the scalp and temporalis muscle on the same side removed in order to eliminate errors caused by isotope clearance from any extracranial tissues. A thin catheter was inserted into the superior sagittal sinus in order to measure sagittal sinus pressure and oxygen content. Cerebral oxygen consumption $\left(\mathrm{CMRO}_{2}\right)$ was calculated from the product of cerebral blood flow (CBF) and the arteriovenous oxygen content difference. Intracranial pressure was recorded either from a cisternal needle or from a sagittal sinus catheter. Samples of CSF $(1 \mathrm{ml})$ were withdrawn at the first and second stages for acid base and lactate analyses.

Angiography was performed in the first seven animals only, because of anxiety over effects on cerebrovascular reactivity (Grubb et al., 1974; Herrschaft et al., 1974). At least 30 minutes were allowed to elapse after each angiogram (maximum of three per animal) before any measurements of CBF were made. The contrast medium used was $2 \mathrm{ml}$ meglumine iothalamate (Conray 280), warmed beforehand to $37^{\circ} \mathrm{C}$. After stable baseline measurements of CBF had been achieved the response to hypercapnia was assessed by adding carbon dioxide to the inspiratory gases to raise $\mathrm{PaCO}_{2}$ to approximately $55 \mathrm{mmHg}$. The response to changing blood pressure will be reported in a separate paper.

At the end of the procedure 10 of the 11 animals were placed supine before perfusionfixation (Brierley et al., 1969; Fitch et al., 1978a). After heparinisation (1000 IU/kg), a thoracotomy was performed and a cannula secured in the proximal part of the arch of the aorta. After incising the right atrium and clamping the descending aorta, physiological saline was infused briefly at the mean arterial blood pressure. Perfusion was continued at the same pressure with five litres of FAM fixative $(40 \%$ formaldehyde; glacial acetic acid; absolute methanol $1: 1: 8$ ). After perfusion the animals were decapitated and the head stored in the same fixative for 12-24 hours. The brain was then removed and immersion fixed in FAM for a further 24 hours. The hindbrain was then detached by a cut through the midbrain and cerebral hemispheres were cut into slices $8 \mathrm{~mm}$ thick. The brainstem was cut at right angles to its long axis into slices $6 \mathrm{~mm}$ thick and the cerebellum into two slices perpendicular to the folia of the dorsal surface of each hemisphere. Large representative bilateral blocks of brain were embedded in paraffin wax and celloidin. The paraffin sections were stained with haemalum and eosin and by a method combining cresyl violet and Luxol fast blue, and the celloidin sections by cresyl violet. The major cerebral arteries and their branches were prepared by the method of Beesley and Daniel (1956) and stained with haemalum and eosin, van Gieson and Miller's 
method for elastica, and by the methods of Martius scarlet blue and phosphotungstic acid haematoxylin for fibrin.

\section{Results}

NEUROLOGICAL CONDITION

Thirteen animals were injected by the transoptic foramen route: two were discarded. In one animal an orbital haematoma developed. There have been two deaths in the series, both from intracerebral haematomata. This was presumed to be the result of pushing the needle in too far, despite the free return of CSF. Apart from the two deaths the other animals recovered well from the procedure and had no neurological or overt behavioural deficit. Their feeding patterns were unaltered. None developed clinically evident meningitis or wound infections.

\section{HAEMODYNAMIC DATA (TABLE)}

Mean arterial blood pressure in the 11 animals studied one week after subarachnoid haemorrhage was $96 \pm 13 \mathrm{SD} \mathrm{mmHg}(12.8 \pm 1.7 \mathrm{kPa})$. The mean intracranial pressure was $11 \pm 7 \mathrm{mmHg}$ but four animals had an intracranial pressure in the range 15-20 $\mathrm{mmHg}$ at normocapnia $\left(\mathrm{PaCO}_{2}\right.$ in the range $38-42 \mathrm{mmHg}$ ).

Baseline CBF (by the height over area method) was $46 \pm 11 \mathrm{ml} / 100 \mathrm{~g} / \mathrm{min}$ with a range of $32-$ $65 \mathrm{ml} / 100 \mathrm{~g} / \mathrm{min}$. This value is the same as in normal baboons previously studied in Glasgow with this anaesthetic technique.

Cerebral oxygen consumption was $3.20 \pm 0.60 \mathrm{ml}$ $\mathrm{O}_{2} / 100 \mathrm{~g} / \mathrm{min}$ with a range of $2.28-4.29 \mathrm{ml} / \mathrm{O}_{2} /$ $100 \mathrm{~g} / \mathrm{min}$. Again, this value is the same as for normal baboons anaesthetised by this technique. The cisternal CSF lactate and bicarbonate con- centrations were not significantly changed one week after subarachnoid haemorrhage compared to pre-haemorrhage values (before subarachnoid haemorrhage: lactate $2.21 \pm 0.36 \mathrm{SD} \mathrm{mmol} / \mathrm{l}$; bicarbonate $25.3 \pm 4.2 \mathrm{mmol} / \mathrm{l}$; one week after haemorrhage: lactate $2.66 \pm 0.71 \mathrm{mmol} / 1$; bicarbonate $24.3 \pm 5.4 \mathrm{mmol} / 1$ ).

\section{RESPONSE OF CEREBRAL CIRCULATION TO}

\section{HYPERCAPNIA}

The overall response to hypercapnia was significantly impaired one week after subarachnoid haemorrhage in the 11 baboons examined (Table). However, there was considerable variation between animals so that not all animals had an impaired response to hypercapnia. The response to hypercapnia in 30 control baboons was $3.27 \pm$ $1.11 \mathrm{SD} \mathrm{ml} / 100 \mathrm{~g} \mathrm{~min}^{-1} \mathrm{mmHg}^{-1}$ (Pickard and MacKenzie, 1973; MacKenzie et al., 1976; Pickard et al., 1977, 1979; and unpublished observations). One week after a subarachnoid haemorrhage, the response was $1.60 \pm 1.07 \mathrm{SD} \mathrm{ml} 100 \mathrm{~g}^{-1} \mathrm{~min}^{-1}$ $\mathrm{mmHg}^{-1}$ (Student's $t$ test $=4.308: \mathrm{P}<0.001$ ). There was no inverse correlation between intracranial pressure and $\mathrm{CO}_{2}$ response.

\section{ANGIOGRAPHY}

In seven baboons in whom angiography was performed in stage 2 none showed any evidence of segmental vasospasm. More quantitative data were not possible because we had deliberately avoided angiography in stage 1 .

\section{NEUROPATHOLOGY}

As judged by the uniform hardening of the specimens and by the absence of blood in the vessels, perfusion-fixation appeared to be good in all animals. There was no evidence of brain swelling or of internal herniation.

Table Response of the cerebral circulation to hypercapnia, one week after subarachnoid haemorrhage in 11 baboons

\begin{tabular}{|c|c|c|c|c|}
\hline Animal no. & $\begin{array}{l}\text { Baseline CBF } \\
\left(\mathrm{ml} .100 \mathrm{~g}^{-1} \cdot \mathrm{min}^{-1}\right)\end{array}$ & $\begin{array}{l}\text { Baseline BP } \\
(m m H g)\end{array}$ & $\begin{array}{l}I C P \\
(m m H g)\end{array}$ & $\begin{array}{l}\text { Response to } \mathrm{CO}_{2} \\
\left(\mathrm{ml} .100 \mathrm{~g}^{-1} \cdot \mathrm{min}^{-1} \cdot \mathrm{mmHg}^{-1}\right)\end{array}$ \\
\hline $\begin{array}{r}2 \\
3 \\
4 \\
5 \\
6 \\
7 \\
8 \\
10 \\
11 \\
12 \\
13\end{array}$ & $\begin{array}{l}46 \\
57 \\
65 \\
46 \\
55 \\
47 \\
50 \\
34 \\
44 \\
32 \\
32\end{array}$ & $\begin{array}{r}93 \\
99 \\
104 \\
92 \\
94 \\
77 \\
116 \\
91 \\
103 \\
112 \\
74\end{array}$ & $\begin{array}{r}20 \\
7 \\
8 \\
20 \\
17 \\
4 \\
10 \\
0 \\
7 \\
12 \\
16\end{array}$ & $\begin{array}{l}1.59 \\
0.84 \\
0.82 \\
4.27 \\
0.56 \\
0.44 \\
1.56 \\
2.00 \\
2.16 \\
1.43 \\
1.95\end{array}$ \\
\hline $\begin{array}{l}\text { Mean } \\
\text { SD }\end{array}$ & $\begin{array}{l}46 \\
11\end{array}$ & $\begin{array}{l}96 \\
13\end{array}$ & $\begin{array}{r}11 \\
7\end{array}$ & $\begin{array}{l}1.60^{*} \\
1.07\end{array}$ \\
\hline
\end{tabular}

* $\mathbf{P}<0.001$ when compared to control data by Student's $t$ test (see text) ICP = intracranial pressure. 
Microscopy of the brain showed that the cytological artefacts, "the dark cell" and "hydropic cell", were minimal (Cammermeyer, 1961). Apart from a single small focus of selective neuronal necrosis in the cortex of the posterior temporal region of one animal, the brains were normal. There was no evidence of raised intracranial pressure (Adams and Graham, 1976).

No significant abnormalities were seen in the intracranial vessels, and in particular there was no evidence of thrombus formation or of necrosis of the walls of arteries and veins.

Small amounts of blood were present in the subarachnoid space and the meninges also contained a mild infiltrate of polymorphonuclear leucocytes and monocytes.

\section{Discussion}

\section{METHODS}

Before assessing the results obtained in this investigation it is necessary to consider the possible influence of the anaesthetic agents used, the validity of the measurements of cerebral blood flow, and any consequence of the subarachnoid injection of blood on the preparation.

The anaesthetic agents used were those which are thought to influence minimally both cerebral blood flow and cerebral metabolism. There is some divergence of opinion as to the effects of nitrous oxide on cerebral blood flow and cerebral metabolism (Wollman et al., 1965; Laitinen et al., 1967; Theye and Michenfelder, 1968; Sakabe et al., 1978). However, in the present investigation the animals were receiving a constant inspired concentration of nitrous oxide $(70 \%)$. As a result, we felt that any influence nitrous oxide might exert on the cerebral blood flow would not affect the results materially. Indeed, the baseline values for cerebral blood flow (Table) compare closely with those obtained in normal unanaesthetised man (Kety and Schmidt, 1948) and are virtually identical to values obtained in previous groups of animals without intracranial pathology anaesthetised similarly (Fitch et al., 1978b) and subjected to drug-induced hypotension with halothane (Fitch et al., 1976).

The xenon-133 technique for the measurement of cerebral blood flow depends on the tracer being distributed to, and detected from, the brain alone and not being influenced by blood flow through extracranial tissues. To ensure this, the significant anastomotic channels present in the baboon between the circle of Willis and the extracranial tissues were obliterated during the procedure of scalp resection. In addition, it is felt unlikely that the production of the artificial subarachnoid haemorrhage would, in any way, influence the determination of cerebral blood flow. During the actual injection of blood into the suprachiasmatic cistern any tendency to respiratory arrest in the animals was counteracted by the use of controlled ventilation, and once the animals were returned to their cages, apart from the two with intracerebral haematoma, they appeared intact neurologically and remained so until the definitive investigations took place. This was reflected both by the normal baseline values for CBF and cerebral oxygen consumption and the paucity of neuropathological damage. It will be appreciated that presence of the subarachnoid haemorrhage had influenced minimally the systemic circulation.

This preparation is an incomplete replica of the human disease as many patients have evidence of pre-existing arterial disease such as atheroma and hypertension. However, the model allows examination of certain physiological factors without the complicating effects of atheroma or of direct vessel trauma.

\section{PATHOLOGICAL CHANGeS AND THE $\mathrm{CBF} \mathrm{CO}_{2}$ RESPONSE}

Experimental "vasospasm" has been produced in diverse laboratory animals by various methods that include arterial injury and subarachnoid haemorrhage (Heros et al., 1976 for review). Experimental subarachnoid haemorrhage frequently produces angiographic narrowing lasting only one to three days and such "vasospasm" has been demonstrated in the baboon after cisternal injections of blood (Du Boulay et al., 1972). Our limited angiographic studies revealed no segmental vasospasm after one week. Nevertheless, the ultrastructural changes of myonecrosis can be identified in the major cerebral arteries after subarachnoid haemorrhage (Alksne and Greenhoot, 1974; Fein et al., 1974; Tanabe et al., 1978; Tani et al., 1978). Structural changes have also been described in the cerebral vessels of patients dying after subarachnoid haemorrhage (Conway and McDonald, 1972; Hughes and Schianchi, 1978). Hughes and Schianchi (1978) carried out a systematic light microscopic examination of the larger arteries known formerly to have been in vasospasm, and found in the short surviving cases that there was slight swelling of the intima, necrosis of the tunica media, and irregularities of the tunica elastica. These "acute" changes in the vessel wall could be related to the time interval between subarachnoid haemorrhage and death. After some three weeks they were 
replaced by the "late" changes of medial and subendothelial fibrosis. The animals in this study were killed seven days after the induction of subarachnoid haemorrhage, and so it is not surprising that light microscopy of the cerebral vessels failed to identify any significant changes. This does not preclude the possibility of ultrastructural damage, and indeed the experience of other workers in this field strongly suggests that, had electron microscopy been carried out, evidence of myonecrosis might have been found. Work is in progress to explore the possibility that the reduced $\mathrm{CBF} \mathrm{CO}_{2}$ response in our animals is related to ultrastructural change in the intracranial vessels.

While injection of mock CSF alone to mimic the acute rise in intracranial pressure had no persisting effect on the $\mathrm{CBF}$, its $\mathrm{CO}_{2}$ or autoregulatory responses, a reduced response to $\mathrm{CO}_{2}$ was noted acutely after subarachnoid haemorrhage in the rhesus monkey, accompanied by a CSF lactic acidosis (Hashi et al., 1972a, b; Shannon et al., 1972; Petruk et al., 1974; Sugi et al., 1975). In the present study, the cisternal CSF lactate concentration was slightly higher one week after subarachnoid haemorrhage compared to before it, but not significantly so. Bulk cisternal CSF acid-base parameters are notoriously difficult to relate to local cerebral tissue values, and our data cannot be used to confirm or refute the notion that impairment of the $\mathrm{CBF} \mathrm{CO}_{2}$ response or of autoregulation (see Pickard et al., 1979) is related to a cerebral perivascular acidosis (Paulson, 1971; Symon et al., 1973), particularly as the source of the lactate in haemorrhagic CSF is probably from red cell metabolism rather than from ischaemic brain (Froman and CramptonSmith, 1966; Shannon et al., 1972; Sugi et al., 1975).

The normal level of cerebral oxygen consumption contradicts the possibility that the reduction in $\mathrm{CBF} \mathrm{CO}_{2}$ response is secondary to changes in cerebral oxygen consumption (Fujishima et al., 1971; Fein, 1975). Intracranial pressure was not raised: hence the reduction in $\mathrm{CBF} \mathrm{CO}_{2}$ response cannot be explained on the basis of reduced levels of cerebral perfusion pressure, particularly as there was no change of baseline CBF.

The reduced response to hypercapnia indicates that the cerebrovascular response to local tissue acidosis will also be impaired after subarachnoid haemorrhage. This may be one of the factors responsible for the poor results associated with early surgical intervention, even in the absence of cerebral vasospasm on angiography.
We are grateful to Dr P. Macpherson, consultant neuroradiologist, for reviewing the angiograms, to the nursing and technical staff of the Wellcome Surgical Research Institute, University of Glasgow, for their skilled assistance, and to Mrs W. McDermid and Mrs R. Burgess for typing the manuscript. The work was supported by funds from the Medical Research Council. Dr Boisvert was in receipt of a Medical Research Council (Canada) Research Fellowship.

\section{References}

Adams, C. B. T., Fearnside, M. R., and O'Laoire, $\frac{\bar{m}}{\widehat{D}}$ S. A. (1978). An investigation with serial angio- $\unrhd$ graphy into the evolution of cerebral arterial spasm \& following aneurysm surgery. Journal of Neurosurgery, 49, 805-815.

Adams, J. H., and Graham, D. I. (1976). The relationship between ventricular fluid pressure and the $\stackrel{\omega}{\sigma}$ neuropathology of raised intracranial pressure. Neuropathology and Applied Neurobiology, 2, 323332.

Alksne, J. F., and Greenhoot, J. H. (1974). Experimental catecholamine-induced chronic cerebrab $\vec{O}$ vasospasm. Journal of Neurosurgery, 41, 440-445.

Beesley, R .A., and Daniel, P. M. (1956). A simpl原 N method for preparing serial blocks of tissuẹ 울 Journal of Clinical Pathology, 9, 267-268.

Boisvert, D. P., Overton, T. R., Weir, B., and Grace M. G. (1978). Cerebral arterial responses to ing duced hypertension following subarachnoid hemo rhage in the monkey. Journal of Neurosurgery, 49 75-83.

Boisvert, D. P. J., Weir, B. K., Overton, T. R., ฮै Reiffenstein, R., and Grace, M. G. (1977). Cerebrovascular responses to subarachnoid blood and serotonin in the monkey. Acta Neurologica Scandinavica, 56, Supplement 64, 322-323.

Du Boulay, G. H., Symon, L., Shah, S., Dorsch, 。ँ N. W. C., and Ackerman, R. (1972). Cerebral $\stackrel{\mathbb{Q}}{\varrho}$ arterial reactivity and spasm after subarachnoid $\overrightarrow{\vec{P}}$ haemorrhage. Proceedings of the Royal Society of Medicine, 65, 80-82.

Brierley, J. B., Brown, A. W., Excell, B. J., and Meldrum, B. S. (1969). Brain damage in the rhesus monkey resulting from profound arterial hypotension. I. Its nature, distribution and general physiological correlates. Brain Research, 13, 68100.

Cammermeyer, J. (1961). The importance of avoiding "dark" neurons in experimental neuropathology. Acta Neuropathologica (Berlin), 1, 245-270.

Conway, L. W., and McDonald, L. W. (1972). Structural changes of the intradural arteries following subarachnoid hemorrhage. Journal of Neurosurgery, 37, 715-723.

Fein, J. M., Flor, W. J., Cohn, S. L., and Parkhurst, J. (1974). Sequential changes of vascular ultra- 
structure in experimental cerebral vasospasm. Journal of Neurosurgery, 41, 49-58.

Fein, J. M. (1975). Cerebral energy metabolism after subarachnoid hemorrhage. Stroke, 6, 1-8.

Fisher, C. M., Roberson, G. H., and Ojemann, R. G. (1977). Cerebral vasospasm after ruptured aneurysm. Stroke, 8, 11.

Fitch, W., Ferguson, G. G., Sengupta, D., Garibi, J., and Harper, A. M. (1976). Autoregulation of cerebral blood flow during controlled hypotension in baboons. Journal of Neurology, Neurosurgery, and Psychiatry, 39, 1014-1022.

Fitch, W., Jones, J. V., Graham, D. I., MacKenzie, E. T., and Harper, A. M. (1978a). Effects of hypotension induced by halothane, on the cerebral circulation in baboons with experimental renovascular hypertension. British Journal of Anaesthesia, 50, 119-125.

Fitch, W., McGeorge, A. P., and MacKenzie, E. T. (1978b). Anaesthesia for studies of the cerebral circulation: a comparison of phencyclidine and althesin in the baboon. British Journal of Anaesthesia, 50, 985-991.

Froman, C., and Crampton-Smith, A. (1967). Metabolic acidosis of the cerebrospinal fluid associated with subarachnoid haemorrhage. Lancet, 1, 965967.

Fujishima, M,. Scheinberg, P., Busto, R., and Reinmuth, O. M. (1971). The relation between cerebral oxygen consumption and cerebrovascular reactivity to carbon dioxide. Stroke, 2, 251-257.

Grubb, R. L. Jr., Hernandez-Perez, M. J., Raichle, M. E., and Phelpes, M. E. (1974). Effects of iodinated contrast agents on autoregulation of cerebral blood flow. Stroke, 5, 155-160.

Harper, A. M., Deshmukh, V. D., Sengupta, D., Rowan, J. O., and Jennett, W .B. (1972). The effect of experimental spasm on the $\mathrm{CO}_{2}$ response of cerebral blood flow in primates. Neuroradiology, 3, 134-136.

Hashi, K., Meyer, J. S., Shinmaru, S., Welch, K. M. A., and Teraura, T. (1972a). Cerebral hemodynamic and metabolic changes after experimental subarachnoid hemorrhage. Journal of the Neurological Sciences, 17, 1-14.

Hashi, K., Meyer, J. S., Shinmaru, S., Welch, K. M. A., and Teraura, T. (1972b). Changes in cerebral vasomotor reactivity to $\mathrm{CO}_{2}$ and autoregulation following experimental subarachnoid hemorrhage. Journal of the Neurological Sciences, $17,15-22$.

Heros, R. C., Zervas, N. T., and Negoro, M. (1976). Cerebral vasospasm. Surgical Neurology, 5, 354362.

Herrschaft, H., Glein, F., and Schmidt, H. (1974). The effects of angiographic contrast media on regional cerebral blood flow and haemodynamics in man. Neuroradiology, 7, 95-103.

Høedt-Rasmussen, K., Sveinsdottir, E., and Lassen, N .A. (1966). Regional cerebral blood flow in man determined by intraarterial injection of radioactive inert gas. Circulation Research, 18, 237-247.

Hughes, J. T., and Schianchi, P. M. (1978). Cerebral artery spasm. Journal of Neurosurgery, 48, 515525.

Jennett, B., Miller, J. D., and Harper, A. M. (1976). Effect of Carotid Artery Surgery on Cerebral Blood Flow. Excerpta Medica: Amsterdam, London, New York.

Kety, S. S., and Schmidt, C. F. (1948). The nitrous oxide method for the quantitative determination of cerebral blood flow in man: theory, procedure and normal values. Journal of Clinical Investigation, 27, 476-483.

Laitinen, L. V., Johansson, G. C., and Tarktanen, L. (1967). The effect of nitrous oxide on pulsatile cerebral impedance and cerebral blood flow. British Journal of Anaesthesia, 39, 781-785.

Löfgren, J., and Zwetnow, N. N. (1972). Kinetics of arterial and venous hemorrhage in the skull cavity. In Intracranial Pressure, pp. 155-159. Edited by M. Brock and H. Dietz. Springer Verlag: Berlin.

MacKenzie, E. T., McCulloch, J., and Harper, A. M. (1976). Influence of endogenous norepinephrine on cerebrospinal blood flow and metabolism. American Journal of Physiology, 231, 489-494.

McQueen, J. D., and Jeanes, L. D. (1962). Influence of hypothermia on intracranial hypertension. Journal of Neurosurgery, 19, 277-288.

Millikan, C. H. (1975). Cerebral vasospasm and ruptured intracranial aneurysms. Archives of Neurology (Chicago), 32, 433-449.

Paulson, O. B. (1971). Cerebral apoplexy (stroke): pathogenesis, pathophysiology and therapy as illustrated by regional cerebral blood flow measurements in the brain. Stroke, 2, 327-360.

Petruk, K. C., Weir, B. K., and Marriott, M. R. (1973). Clinical grade, regional cerebral blood flow and angiographical spasm in the monkey after subarachnoid and subdural hemorrhage. Stroke, 4, 431-445.

Petruk, K. C., Weir, B. K., Overton, T. R., Marriott, M. R., and Grace, M. G. (1974). The effect of graded hypocapnia and hypercapnia on regional cerebral blood flow and cerebral vessel calibre in the Rhesus monkey: study of cerebral hemodynamics following subarachnoid hemorrhage and traumatic internal carotid spasm. Stroke, 5, 230-246.

Pickard, J. D., and MacKenzie, E. T. (1973). Inhibition of prostaglandin synthesis and the response of baboon cerebral circulation to carbon dioxide. Nature New Biology, 245, 187-188.

Pickard, J. D., Durity, F., Welsh, F. A., Langfitt, T. W., Harper, A. M., and MacKenzie, E. T. (1977). Osmotic opening of the blood brain barrier: value in pharmacological studies on the cerebral circulation. Brain Research, 122, 170-176.

Pickard, J. D., Boisvert, D. P. J., Graham, D. I., and Fitch, W. (1979). Late effects of subarachnoid haemorrhage on the response of the primate cere- 
bral circulation to drug-induced changes in arterial blood pressure. Journal of Neurology, Neurosurgery, and Psychiatry, 42, 899-903.

Sakabe, T., Kuramoto, T., Inoue, S., and Takeshita, H. (1978). Cerebral effects of nitrous oxide in the dog. Anesthesiology, 48, 195-200.

Shannon, D. C., Shore, N., and Kazemi, H. (1972). Acid-base balance in hemorrhagic cerebrospinal fluid. Neurology (Minneapolis), 22, 585-589.

Sugi, T., Fujishima, M., and Omae, T. (1975). Lactate and pyruvate concentrations and acid-base balance of cerebrospinal fluid in experimentally induced intracerebral and subarachnoid hemorrhage in dogs. Stroke, 6, 715-719.

Symon, L., Held, K., and Dorsch, N. W. C. (1973). A study of regional autoregulation in the cerebral circulation to increased perfusion pressure in normocapnia and hypercapnia. Stroke, 4, 139-147.

Tanabe, Y., Sakata, K., Yamada, H., Ito, T., and Takada, M. (1978). Cerebral vasospasm and ultrastructural changes in cerebral arterial wall. Journal of Neurosurgery, 49, 229-238.

Tani, E., Yamagata, S., and Ito, Y. (1978). Intercellular granules and vesicles in prolonged cerebral vasospasm. Journal of Neurosurgery, 48, 179-189.

Theye, R. A., and Michenfelder, J. D. (1968). The effect of nitrous oxide on canine cerebral metabolism. Anesthesiology, 29, 1119-1124.

Wollman, H., Alexander, S. C., Cohen, P. J., Smith, T. C., and Chase, P. F. (1965). Cerebral circulation during general anesthesia and hyperventilation in man. Anesthesiology, 26, 329-334. 